\title{
HIDROGEOLOGÍA DE UN SECTOR DE LA MARGEN IZQUIERDA DEL RÍO VIRILLA, PROVINCIA DE SAN JOSÉ, COSTA RICA
}

\author{
Gunther Schosinsky \& Asdrúbal Vargas \\ Escuela Centroamericana de Geología, Apdo. 2-14; 2060 Universidad de Costa Rica. \\ E-mail: gschosin@cariari.ucr.ac.cr/avargas@cariari.ucr.ac.cr
}

(Recibido 1/10/1999; Aceptado 26/11/1999)

\begin{abstract}
For the first time the hidrogeological features of an area near to the left border of Virilla river, in the capital of San José, were investigated. The basement of the area is the sedimentary Formación Pacacua, covered by a secuence of flows lava, ignimbrites, tuff layers, mud flows and ashes. The lava flows contain the most important aquifers of the area signed as Colima Inferior and Colima Superior. The ignimbrite flows form aquitarde and the mud flows low potential acuifer. The direction of the flow of groundwater was defined from East toWest and the recharge area is situated in the eastern part of San José. In some parts the main rivers of the area are influent and recharge directly water to the upper aquifer.
\end{abstract}

\begin{abstract}
RESUMEN: Se investigaron las características hidrogeológicas de un sector de la margen izquierda del río Virilla. La geología está constituida por un basamento sedimentario asociado a la Formación Pacacua, sobreyacido por una secuencia volcánica compuesta por coladas de lava, flujos de ignimbrita, capas de toba y lahares cubiertos por capas de ceniza. Las formaciones productoras de agua corresponden a las lavas denominadas Colima inferior y Colima Superior, que se caracterizan como acuíferos de tipo poroso o fisurado. Estos acuíferos en ciertos sectores son confinados por acuitardos, conformados por los flujos de ignimbritas. Los lahares constituyen acuíferos de bajo potencial. La dirección de flujo del agua subterránea tiene una dirección E-W, con una posible descarga de agua subterránea en el río Virilla.
\end{abstract}

\section{INTRODUCCIÓN}

La margen izquierda del río Virilla ha sido poco estudiada desde el punto de vista hidrogeológico, aunque existen gran cantidad de perforaciones realizadas por instituciones como SENAS o por empresas privadas que permiten obtener un registro de la litoestratigrafía del área e información muy valiosa sobre la hidrogeología. Estudios geológicos e hidrogeológicos relacionados con esta investigación han sido realizados por Denyer \& Arias,1990; Denyer \& Arias, 1991; Echandi, 1981; Fernández, 1969; Kussmaul,1988; Protti, et. al., 1983. El área de estudio abarca un sector comprendido por las coordenadas en latitud 211000218000 y en longitud de 521000-527000 de la hoja topográfica Abra. La topografía es relativamente plana con leves ondulaciones del terreno e incluye las poblaciones de Rohmoser, Pavas y un sector de Hatillo (Fig. 1).

En este sector se ha detectado contaminación del agua subterránea, la cual es utilizada por numerosas industrias y poblaciones, por lo tanto este estudio es básico para desarrollar investigaciones posteriores sobre el origen de la contaminación. Los objetivos del presente trabajo están definidos por la investigación de la geología del área, la identificación de las unidades hidrogeológicas principales, la dirección de flujo del agua subterránea y las probables zonas de recarga. La metodología utilizada ha sido la recopilación de información de los archivos de pozos del SENARA, la interpretación de la información, la construcción de perfiles estratigráficos y la interpolación de los niveles de agua en puntos discretos para determinar la dirección de flujo del agua subterránea.

\section{GEOLOGÍA}

En el área de estudio se encuentran rocas de tipo sedimentario y volcánico, definidas las primeras por la Formación Pacacua, considerado el basamento del área de estudio y las segundas 


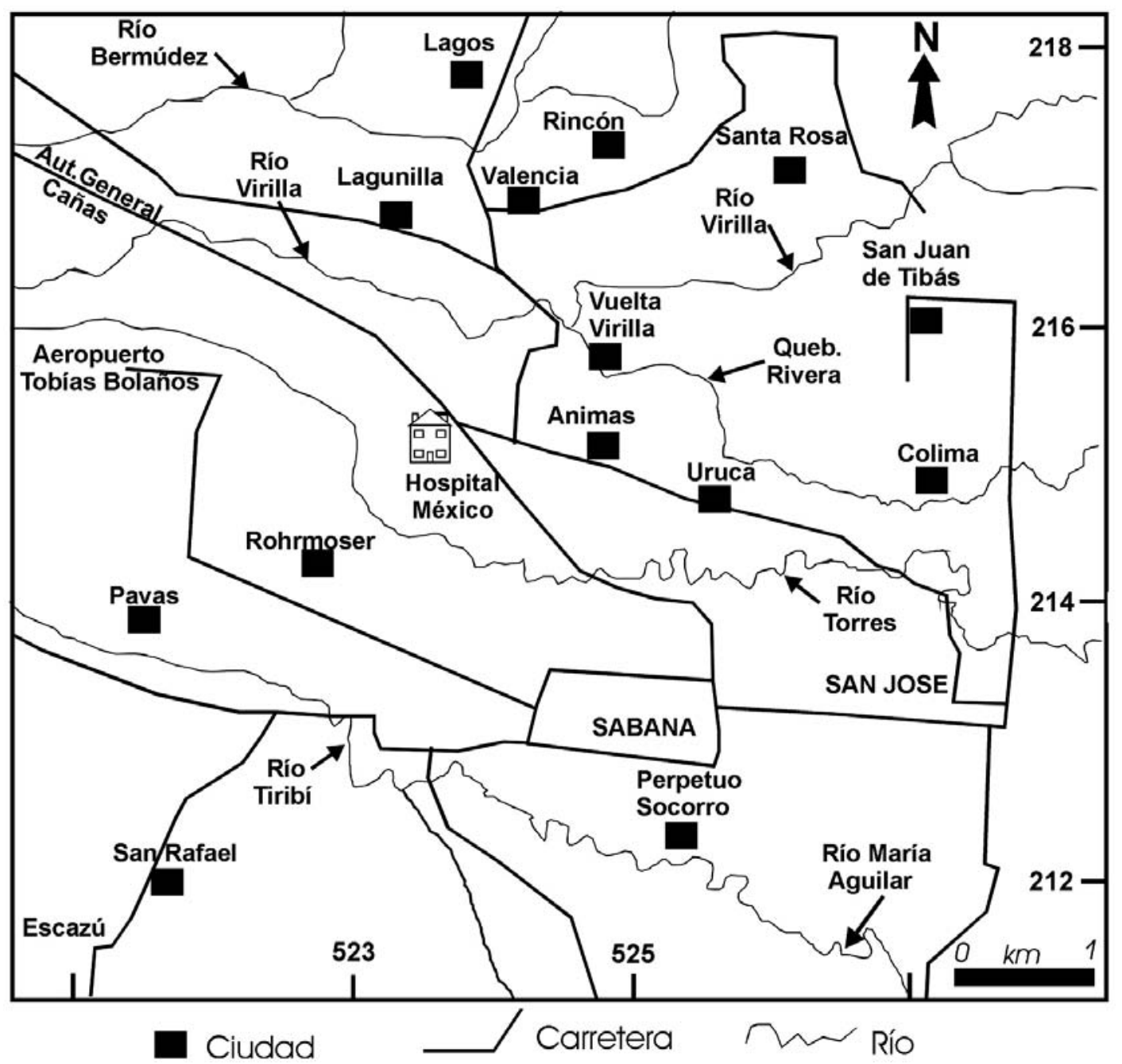

Fig. 1: Ubicación geográfica del área de estudio.

por las formaciones Colima, Tiribí y Barba (aunque los nombres estratigráficos correspondientes son Lavas Intracañón, Avalancha Ardiente y Barba), con una cobertura compuesta por tobas, lahares y cenizas. La figura 2 muestra la distribución de las unidades geológicas de acuerdo a Denyer \& Arias (1990).

\section{ASPECTOS HIDROGEOLÓGICOS}

En la zona de investigación existen alrededor de 200 perforaciones, de las cuales un gran número son utilizadas como pozos de abastecimiento de agua para la industria y para uso doméstico (Fig. 2). Las principal unidad hidrogeológica es la Formación Colima la cual es captada por numerosos pozos. Por su parte los flujos de ignimbrita, los horizontes de toba y los depósitos laháricos constituyen acuitardos, aunque en algunos sectores presentan conductividades hidráulicas que favorecen la transmisión de agua subterránea. La Formación Pacacua, por su amplia proporción arcillosa, baja permeabilidad y posición estratigráfica, se considera el basamento del área de estudio. 

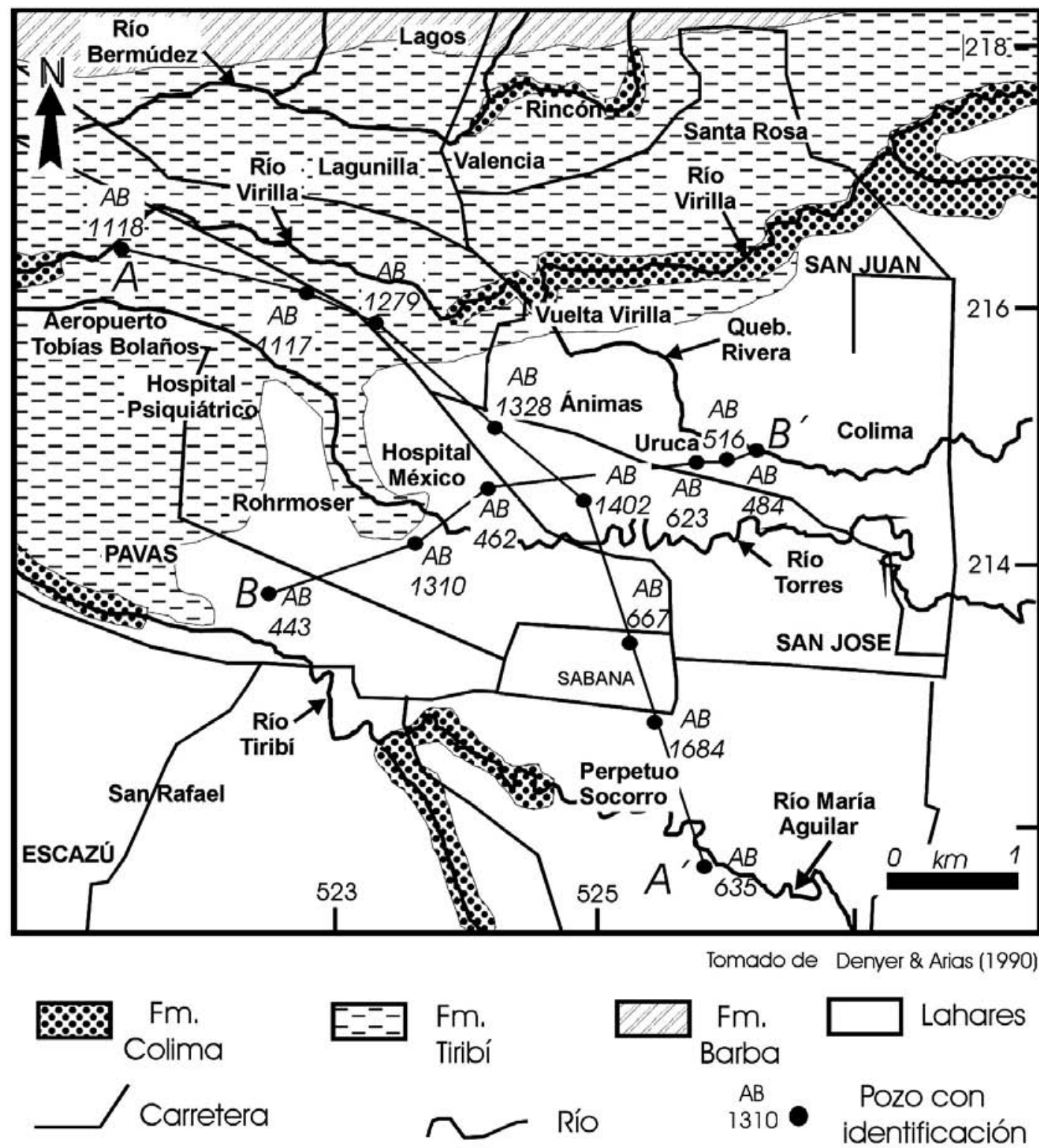

Fig. 2: Geología del área de estudio, pozos con identificación y perfiles hidrogeológicos.

Formación Pacacua

Aflora al sur del área de estudio y está constituida por un conglomerado muy meteorizado y en ocasiones muy fracturado de color rojizo a morado (pozo AB-101). Algunos pozos se encuentran captando esta formación sin embargo la capacidad específica es muy baja. Ninguna de las perforaciones del área logran cortar completamente esta formación, por lo cual se desconoce su espesor.

Formación Colima

Está compuesta por dos unidades que se denominan Colima Inferior y Colima Superior. La unidad Colima Inferior tiene un espesor promedio de $17 \mathrm{~m}$ (Cuadro 1), aunque este 
puede ser mayor ya que las perforaciones no cortan en su totalidad esta unidad (Figs. 3 y 4). Se presenta como una lava de textura porfirítica muy vesicular y fracturada de color negro (pozos AB-1279 y AB-1402) con una permeabilidad aparente muy alta. Está sobreyacida por una capa de toba y de ignimbrita de permeabilidad baja.
La toba es de color café muy heterogénea con tramos arenosos o arcillosos y con bloques volcánicos de tamaño centimétrico. La permeabilidad aparente es de baja a muy baja. La ignimbrita presenta en ocaciones una moderada conductividad hidráulica. Está infrayacida por sedimentos marinos de la Formación Pacacua (Fig. 4).

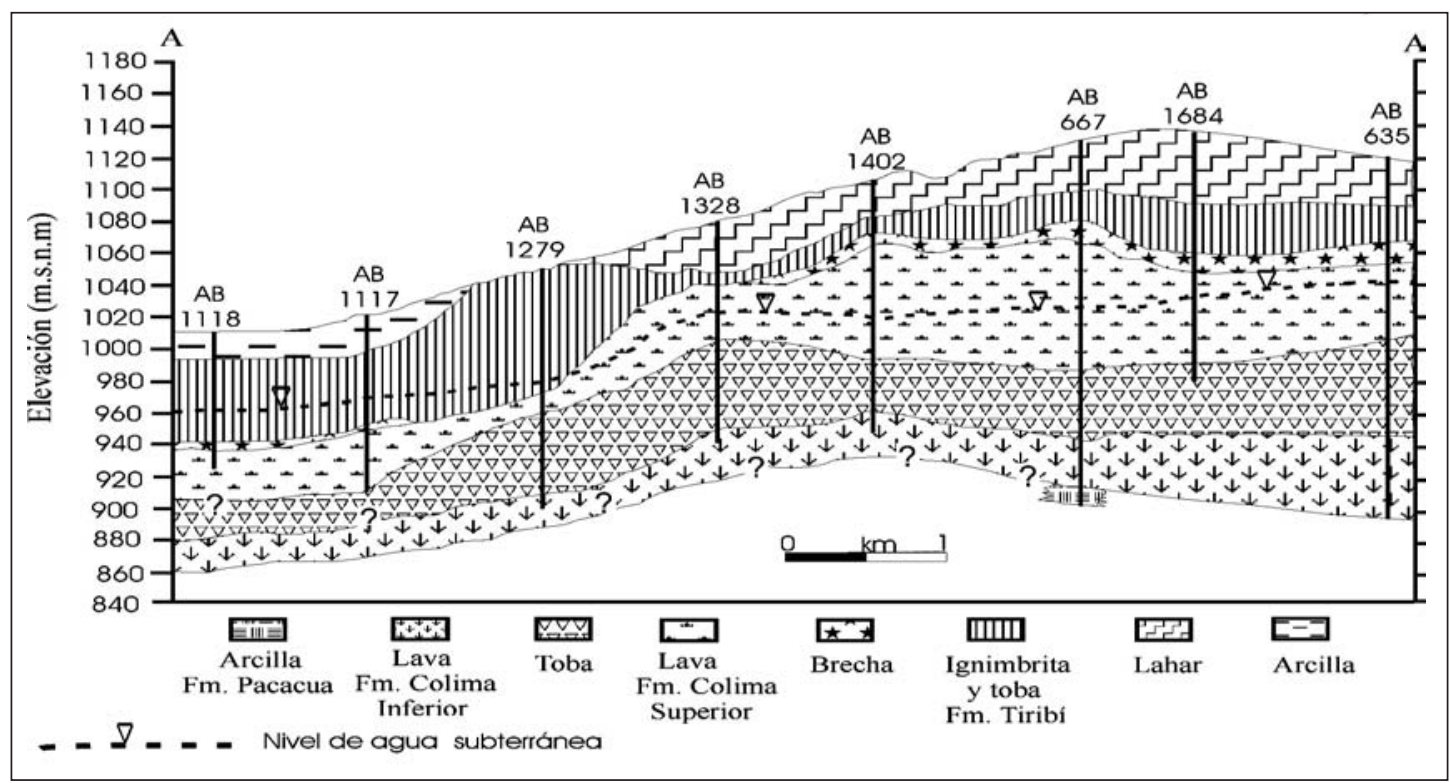

Fig. 3: Perfil hidrogeológico A-A', construido a partir de la información de perforaciones.

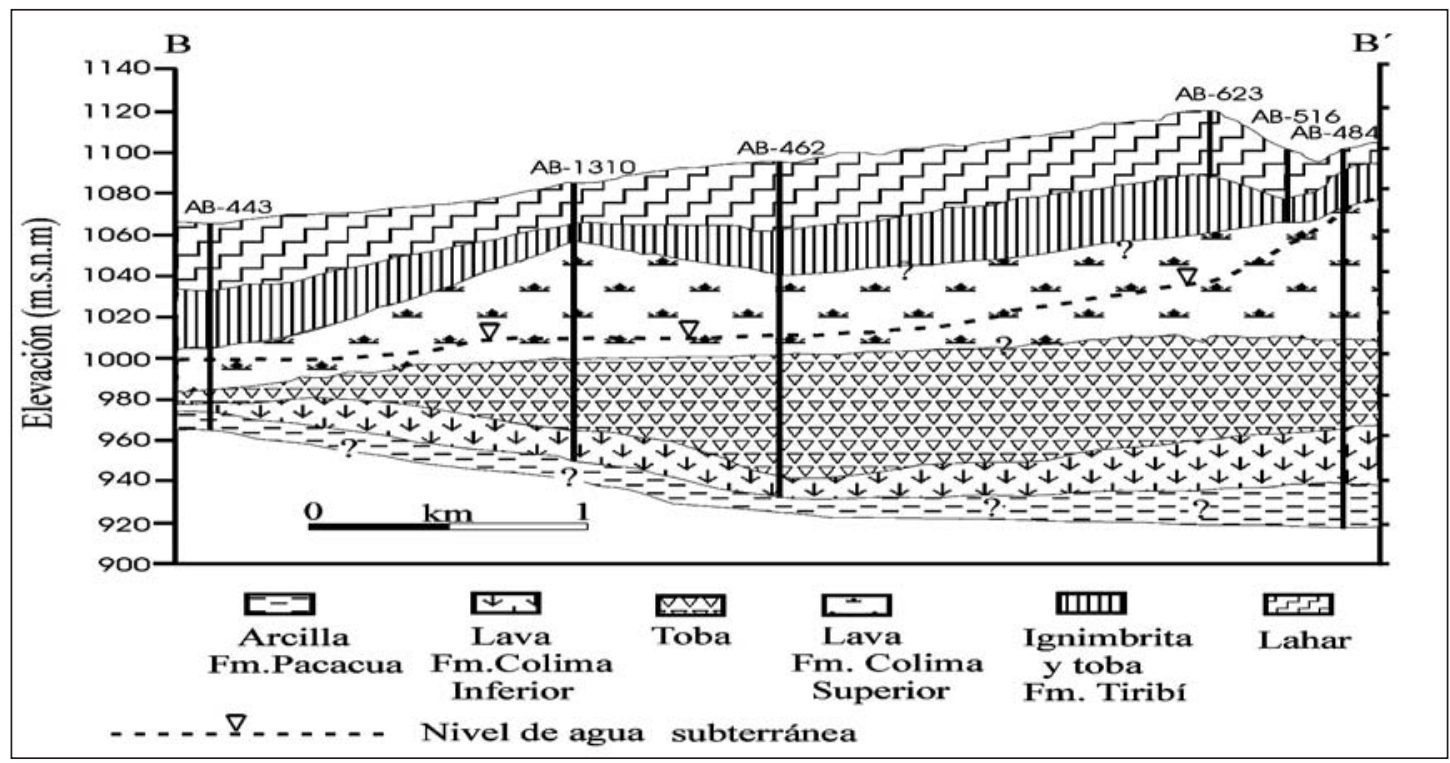

Fig. 4: Perfil hidrogeológico B-B', construido a partir de la información de perforaciones. 
Cuadro 1

Características de la unidad hidrogeológica Colima Inferior

\begin{tabular}{|c|c|c|c|c|c|c|}
\hline Perforación & Lat. & Long. & $\begin{array}{c}\text { Techo } \\
\text { (m.s.n.m) }\end{array}$ & $\begin{array}{c}\text { Piso } \\
\text { (m.s.n.m) }\end{array}$ & $\begin{array}{l}\text { Nivel Estático } \\
\text { (m.s.n.m) }\end{array}$ & $\begin{array}{l}\text { Espesor } \\
\text { (m) }\end{array}$ \\
\hline AB-443 & 21370 & 52240 & 978 & 974 & - & 4 \\
\hline AB-462 & 21465 & 52419 & 942 & 936 & - & 6 \\
\hline AB-484 & 21490 & 52620 & 965 & 946 & - & 19 \\
\hline AB-635 & 21160 & 52590 & 944 & 898 & - & 46 \\
\hline AB-667 & 21318 & 52522 & 942 & 916 & - & 26 \\
\hline AB-1279 & 21580 & 52522 & 908 & 895 & - & 13 \\
\hline AB-1310 & 21420 & 52345 & 964 & 951 & 999 & 13 \\
\hline AB-1328 & 21507 & 52415 & 950 & 941 & - & 9 \\
\hline AB-1402 & 21437 & 52480 & 960 & 943 & 995 & 17 \\
\hline
\end{tabular}

Cuadro 2

Características geométricas de la unidad hidrogeológica Colima Superior

\begin{tabular}{|c|c|c|c|c|c|c|}
\hline Perforación & Lat. & Long. & $\begin{array}{c}\text { Techo } \\
\text { (m.s.n.m) }\end{array}$ & $\begin{array}{c}\text { Piso } \\
\text { (m.s.n.m) }\end{array}$ & $\begin{array}{l}\text { Nivel Estático } \\
\text { (m.s.n.m) }\end{array}$ & $\begin{array}{c}\text { Espesor } \\
\text { (m) }\end{array}$ \\
\hline AB-443 & 21370 & 52240 & 1005 & 984 & 1005 & 21 \\
\hline AB-462 & 21465 & 52419 & 1040 & 1006 & ND & 34 \\
\hline AB-484 & 21490 & 52620 & 1075 & 1006 & ND & 69 \\
\hline AB-635 & 21160 & 52590 & 1070 & 1010 & ND & 60 \\
\hline AB-667 & 21318 & 52522 & 1085 & 986 & 1025 & 84 \\
\hline AB-1117 & 21613 & 52257 & 952 & 915 & 960 & 37 \\
\hline AB-1118 & 21635 & 52165 & 940 & 905 & ND & 35 \\
\hline AB-1279 & 21580 & 52522 & 970 & 960 & ND & 10 \\
\hline AB-1310 & 21420 & 52345 & 1057 & 1022 & 999 & 35 \\
\hline AB-1328 & 21507 & 52415 & 1040 & 1007 & ND & 33 \\
\hline AB-1402 & 21437 & 52480 & 1073 & 995 & ND & 69 \\
\hline AB-1684 & 21284 & 52532 & 1060 & 984 & ND & 26 \\
\hline AB-1788 & 21365 & 52445 & 1060 & 1028 & ND & 72 \\
\hline
\end{tabular}

La unidad Colima Superior tiene un espesor promedio de $45 \mathrm{~m}$, aumenta hacia el este de la zona de estudio y es cortada por numerosas perforaciones como se muestra en el cuadro 2. Aflora en el río María Aguilar a la altura de Perpetuo Socorro, río Tiribí cerca de la localidad de Pavas y el río Virilla en diversas localidades (Fig. 2).

Es una lava andesítica de color café a grisáceo, densa pero con secciones vesiculares de gran porosidad. En las secciones densas existe una fracturación que genera una porosidad aceptable. Hacia la base o el techo aparece una autobrecha compuesta por fragmentos de lava densa o lava vesicular mezclada con material terroso calcinado de color rojo. A partir de las isohipsas del techo de la unidad Colima Superior se observa un buzamiento NW, el cual es muy probable que tenga influencia sobre la dirección del agua subterránea (Fig. 5). La unidad Colima Inferior se encuentra separada de la unidad Colima Superior por una capa de toba de espesor variable.

\section{Formación Tiribí}

Está constituida por ignimbritas y tobas con un espesor promedio de $30 \mathrm{~m}$ (Cuadro 3) y se extiende en la totalidad del área de investigación y aflora en el río Torres a la altura del Hospital México y en varios tramos del río Virilla. La ignimbrita es de color gris constituida de fragmentos piroclásticos de tamaño lapilli en 


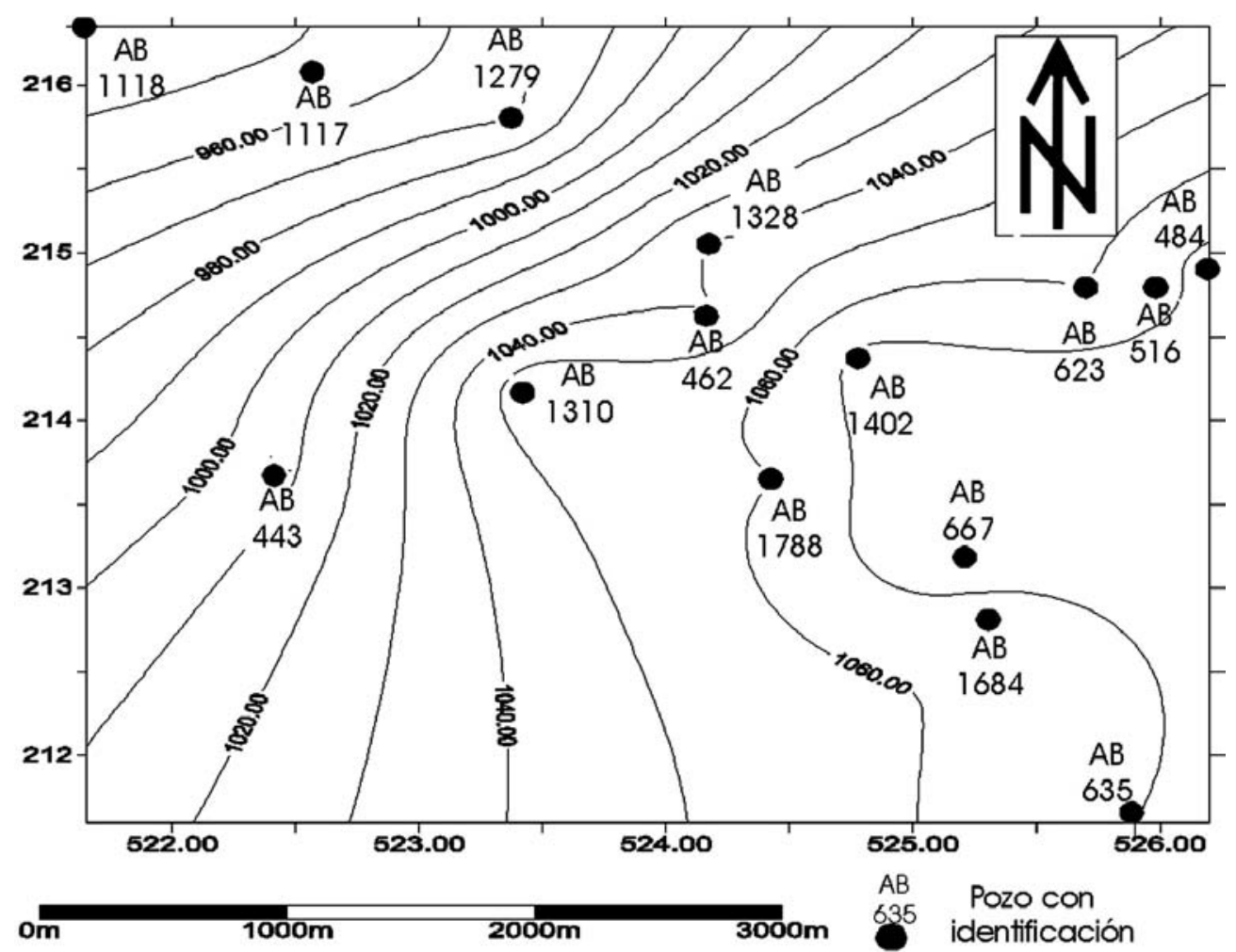

Fig. 5: Mapa de hisohipsas (elevación del techo) de la Formación Colima Superior y pozos con identificación.

una matriz de ceniza, con grandes bombas de escoria negra y vidriosa. En ocaciones presenta fracturación prismática vertical lo cual favorece la percolación de agua hacia niveles más profun- dos, aunque en caudales reducidos. Por su parte, la toba tiene un color pardo a gris con predominancia de lapilli incluidos en una matriz de ceniza con escaza porosidad.

Cuadro 3

Características geométricas de la unidad hidrogeológica Tiribí

\begin{tabular}{|c|c|c|c|c|c|}
\hline Perforación & Lat. & Long. & $\begin{array}{c}\text { Techo } \\
\text { (m.s.n.m) }\end{array}$ & $\begin{array}{c}\text { Piso } \\
\text { (m.s.n.m) }\end{array}$ & $\begin{array}{c}\text { Espesor } \\
\text { (m) }\end{array}$ \\
\hline AB-443 & 21370 & 52240 & 1034 & 1004 & 30 \\
\hline AB-462 & 21465 & 52419 & 1061 & 1040 & 21 \\
\hline AB-484 & 21490 & 52620 & 1093 & 1076 & 17 \\
\hline AB-635 & 21160 & 52590 & 1090 & 1070 & 20 \\
\hline AB-667 & 21318 & 52522 & 1098 & 1083 & 15 \\
\hline AB-1117 & 21613 & 52257 & 997 & 952 & 45 \\
\hline AB-1118 & 21635 & 52165 & 993 & 950 & 43 \\
\hline AB-1279 & 21580 & 52522 & 1050 & 970 & 80 \\
\hline AB-1310 & 21420 & 52345 & 1066 & 1057 & 9 \\
\hline AB- 1328 & 21507 & 52415 & 1048 & 1040 & 8 \\
\hline AB-1402 & 21437 & 52480 & 1082 & 1073 & 9 \\
\hline AB-1684 & 21284 & 52532 & 1086 & 1056 & 30 \\
\hline AB-1788 & 21365 & 52445 & 1086 & 1028 & 58 \\
\hline
\end{tabular}




\section{Lahares y arcillas}

Aparecen en varias de las perforaciones y son de color café, compuestos por fragmentos de lava alterados de tamaño mediano $(1-2 \mathrm{~cm})$ y ocacionalmente del tamaño bloque y partículas piroclásticas de granulometría arenosa a limosa, todo incluido en una matriz arcillificada densa de plasticidad variable. En ocaciones se observan partículas de vidrio negro y de feldespatos. El espesor aparente alcanza $30 \mathrm{~m}$ (AB-443) y se consideran de baja permeabilidad. Presentan una gran extensión en el sector este del área de estudio y afloran en los ríos María Aguilar, Torres y la quebrada Rivera.

\section{ISOFREÁTICAS Y DIRECCIÓN DE FLUJO DEL AGUA SUBTERRÁNEA}

Se seleccionaron datos de elevación de niveles piezométricos de agua subterránea en pozos que representaran los niveles de Colima Superior. Estos datos, en su mayoría se obtuvieron de los archivos del SENARA y algunos de ellos de empresas de perforación privadas. Los datos utilizados se presentan en el cuadro 4, en la cual se muestran varios pozos que no se incluyeron en los cuadros precedentes, pues no disponían de información sobre litología.

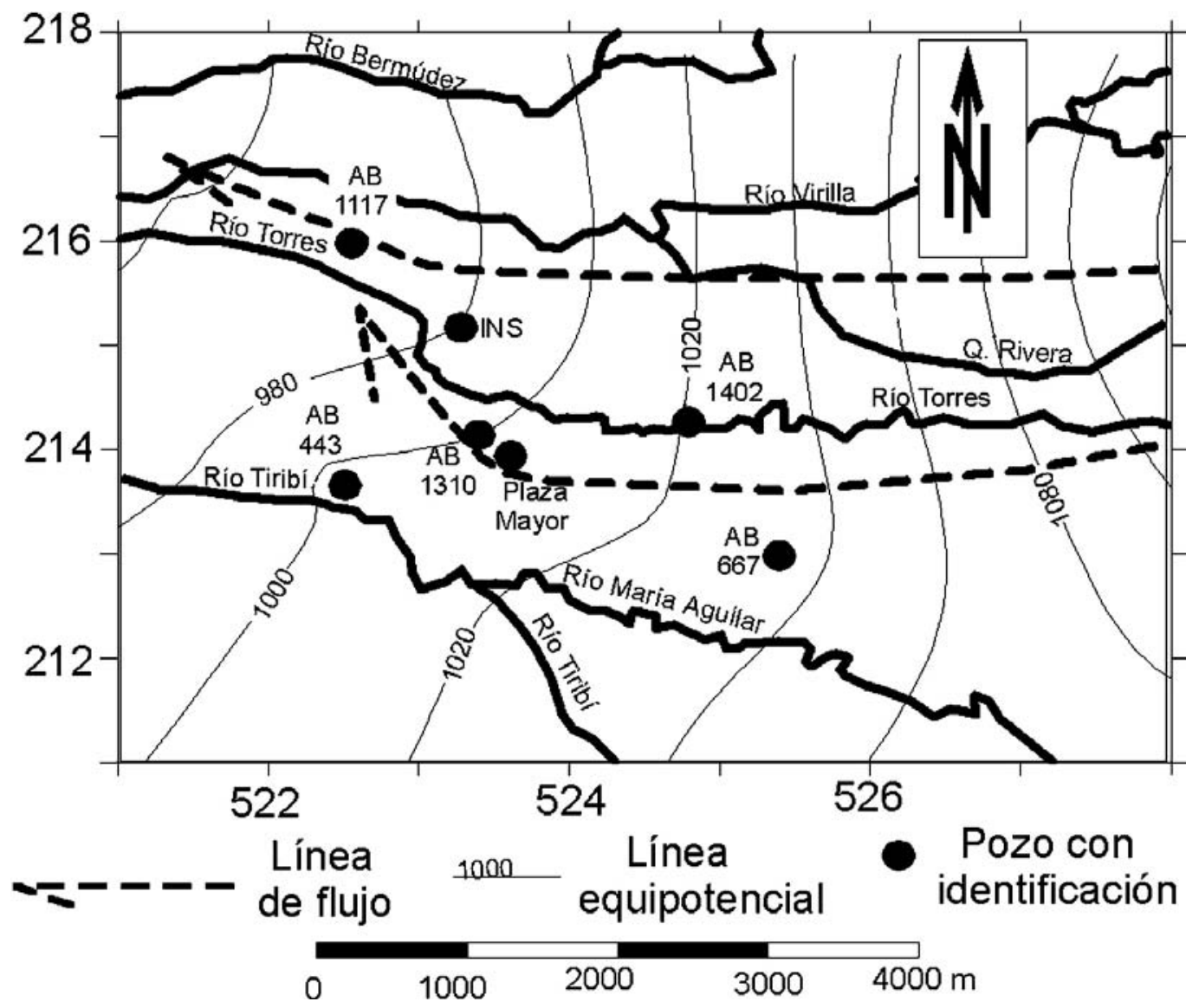

Fig. 6: Dirección del flujo de agua subterránea y líneas equipotenciales en metros sobre nivel del mar construidas a partir de niveles piezométricos en 12 pozos, algunos de ellos ubicados en los márgenes del área de estudio. 
Cuadro 4

Ubicación y elevación del nivel estático de pozos representativos de la Colima Superior, según archivos del SENARA

\begin{tabular}{lccc}
\hline Perforación & $\begin{array}{c}\text { Longitud } \\
(\mathrm{m})\end{array}$ & $\begin{array}{c}\text { Latitud } \\
(\mathrm{m})\end{array}$ & $\begin{array}{c}\text { N.E. } \\
(\mathrm{m} . \mathrm{s} . n . m)\end{array}$ \\
AB 443 & 522400 & 213700 & 1005 \\
AB 1117 & 522570 & 216130 & 960 \\
AB 667 & 525220 & 213180 & 1025 \\
AB 1310 & 523450 & 214200 & 999 \\
INS & 523300 & 215200 & 980 \\
Plaza & 523800 & 214000 & 1009 \\
Mayor & & & \\
AB 1049 & 528350 & 216575 & 1132 \\
AB 520 & 520680 & 217780 & 934.7 \\
AB 449 & 529100 & 215600 & 1158 \\
AB 989 & 525950 & 210950 & 1060 \\
AB 790 & 527750 & 210900 & 1080 \\
AB 543 & 527800 & 210900 & 1063 \\
\hline
\end{tabular}

Con base en los datos del cuadro 4, se graficó el mapa de equipotenciales (isofreáticas) mostrado en la figura 6. Se puede observar que las líneas de flujo provienen del lado este, para descargar principalmente hacia el río Virilla, aproximadamente en las coordenadas 521000523000 de longitud y 216000-217000 de latitud. La dirección de las líneas de flujo (línea de trazos) sugiere que una proporción de la recarga proviene del sector este.

Para analizar las secciones en que el ríos son influentes o efluentes, se realizó un mapa de isoelevaciones de los cauces de los ríos existentes en el área de estudio (Fig. 7) y un mapa de diferencias entre los isoniveles de los cauces de los ríos, menos las elevaciones de las isofreáticas de la unidad Colima Superior (Fig. 8). De esta forma, donde los valores de las isodiferencias es menor a cero, el río recibe agua del acuífero Colima Superior y donde los valores de las isodiferencias es mayor que cero, el río podría

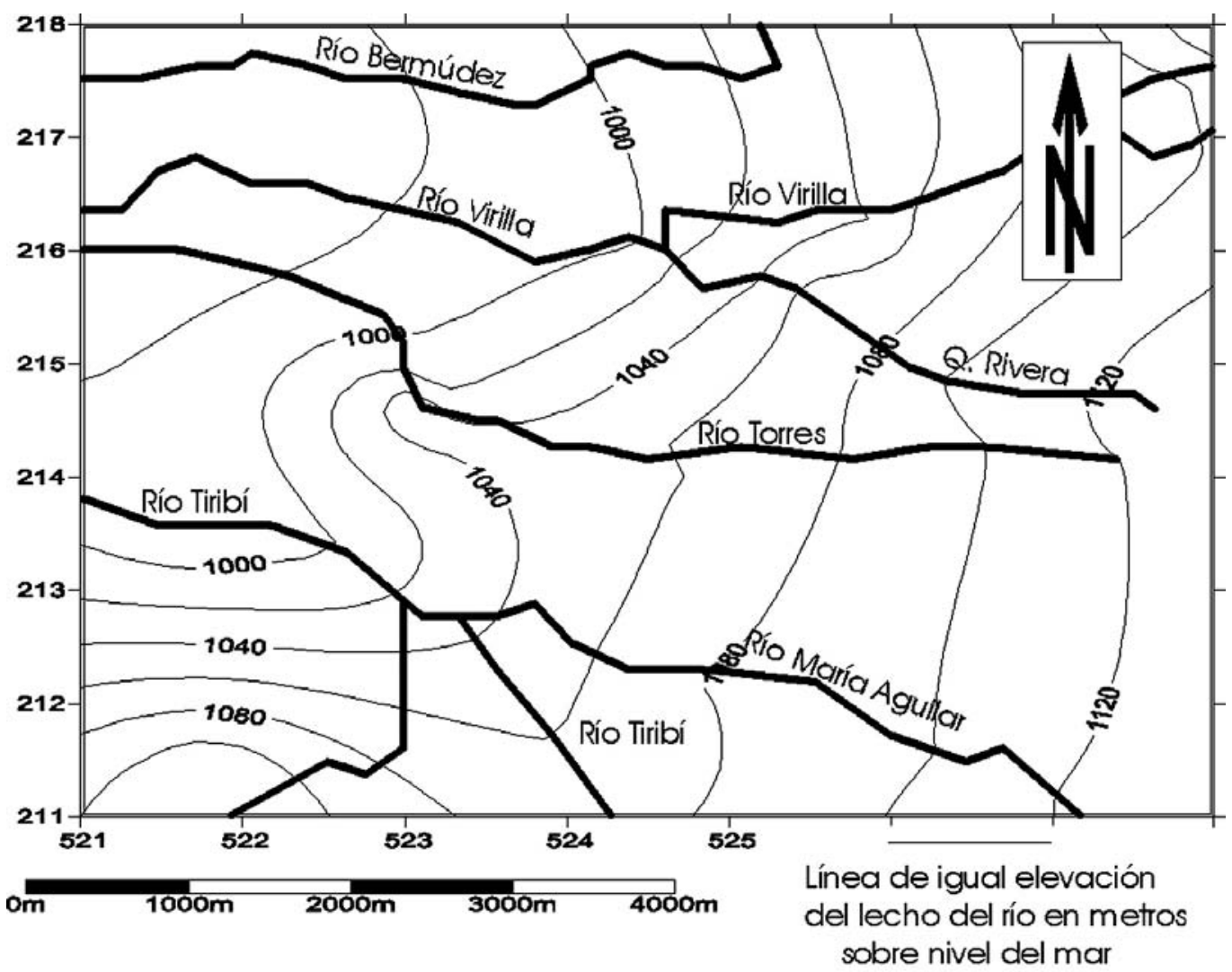

Fig. 7: Isoniveles del lecho de ríos en metros sobre nivel del mar con curvas de nivel cada $20 \mathrm{~m}$. 


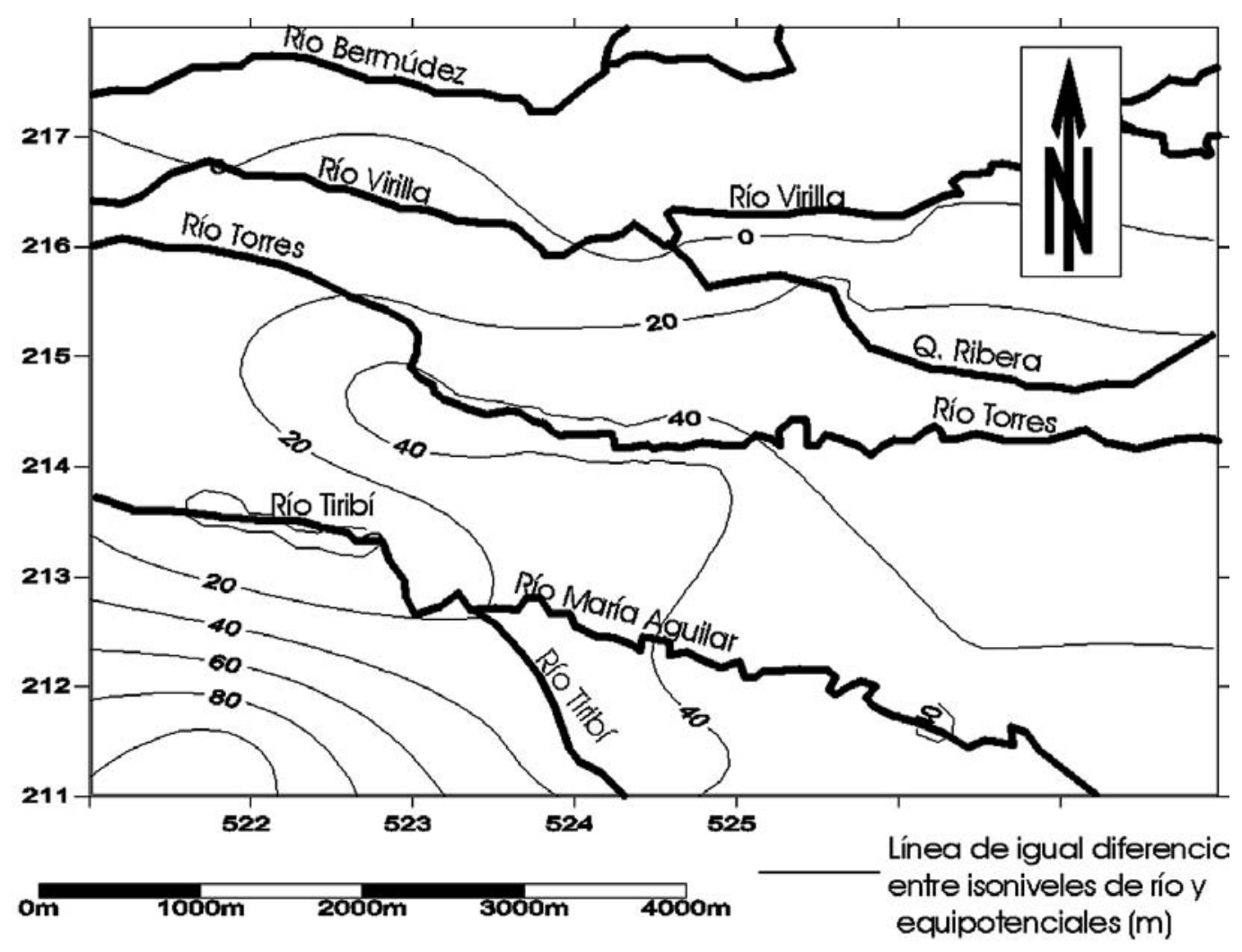

Fig. 8:Mapa de diferencias entre los isoniveles de ríos y equipotenciales de la Formación Colima Superior. Isolíneas mayores de cero indica que el lecho del río se encuentra por encima del nivel freático.

recargar a dicho acuífero si la permeabilidad lo permite. En las coordenadas de latitud 213000214000 y longitud de 521000-522000, el acuífero podría descargar sus aguas en el río Tiribí. Sin embargo en la mayor parte del área de estudio, los cauces de los ríos se encuentran por encima de los niveles de saturación de agua subterránea, lo que sugiere que los ríos Torres, María Aguilar y Tiribí podrían recargar al acuífero. En la figura 6 se puede observar la existencia de líneas de flujo que pasan por debajo y paralelas al cauce del río Torres. Al encontrarse las aguas subterráneas siguiendo un largo trayecto por debajo del río Torres, es muy posible que la calidad química de las aguas del Torres, influya en la calidad química de línea de flujo de aguas subterráneas, que sigue dicha trayectoria, considerando que el río es verdaderamente influente.

\section{CONCLUSIONES}

Las unidad hidrogeológica más importante del área de estudio es la unidad Colima, que consta de dos secciones separadas entre sí por una capa de toba. La unidad Colima Superior tiene un espesor variable con un promedio de $45 \mathrm{~m}$ y la Unidad Inferior de alrededor de $20 \mathrm{~m}$. Ambas unidades están siendo explotadas por medio de pozos de extracción de agua subterránea por lo cual es importante la protección de ambos reservorios. El espesor de las formaciones Colima y Tiribí se incrementa hacia el este y noreste en el área de estudio por lo que es muy probable que los centros de emisión estuvieran situados en esa dirección. Los perfiles hidrogeológicos se construyeron con base en la información existente y con la respectiva interpretación de los materiales descritos en las 
perforaciones, sin embargo, quedan aún en duda ciertos sectores del área de estudio donde no se tiene información ni de perforaciones ni de geología de campo, por lo tanto los perfiles son una aproximación a la representación de la secuencia estratigráfica del área.

La dirección de las líneas de flujo sugiere que parte de la recarga de agua subterránea al acuífero Colima Superior proviene del este del Valle Central, probablemente del área de San Isidro de Coronado o alrededores. La dirección de las líneas de flujo es del este hacia el noroeste, indicando de que el agua subterránea descarga hacia el río Virilla o hacia el río Tiribí. En algunos tramos el río Torres, el río María Aguilar y la quebrada Rivera pueden ser influentes.

Con este estudio se han logrado definir características hidrogeológicas para un área de sumo interés por la presencia de numerosos pozos de abastecimiento de agua, los cuales deben ser protegidos de fuentes de contaminación.

\section{REFERENCIAS}

DENYER, P. \& ARIAS, O., 1990: Geología de la hoja Abra .- Mapa escala 1: 50 000. IGN, San José.
DENYER, P. \& ARIAS, O., 1991: Estratigrafía de la región central de Costa Rica. - Rev. Geol. América Central, 12: 1-59.

ECHANDI, E., 1981: Unidades volcánicas de la vertiente norte de la cuenca del río Virilla. - 123 págs. Universidad de Costa Rica [tesis Lic.].

FERNÁNDEZ, M., 1969: Las unidades hidrogeológicas y los manantiales de la vertiente norte del río Virilla. - 56 págs. SENAS, San José [Informe técnico].

KUSSMAUL, S., 1988: Comparación petrológica entre el piso volcánico del Valle Central y la Cordillera Central de Costa Rica. Ciencia y Tecnología 12(1-2): 109- 116.

PROTTI, E., SIU, D., ZARATE, E., RAMIREZ, P., BERGOEING, J., BRENES, L., ECHANDI, E., MONTERO, W., 1983: Sistema fluvial de Tárcoles, Costa Rica: estudios preliminares sobre geomorfometría y geofactores básicos, contribución a la geografía general de Costa Rica. - 90 págs + mapas, IGNCONICIT, San José. 